\title{
Rapid development of neurosyphilis in a long-standing diabetic
}

\author{
*A. N. GoRSUCH \\ M.A., M.R.C.P. \\ $\dagger$ R. N. THIN \\ M.D., F.R.C.P.E.
}

$\dagger$ P. D. SIMMONS
M.B. M.R.C.P.

*A. G. Cudworth

M.D., Ph.D., F.R.C.P.

Departments of *Diabetes and $\dagger$ Genital Medicine, St Bartholomew's Hospital, London ECIA $7 B E$

\begin{abstract}
Summary
At the age of 50 years, a known diabetic presented with clinical features of diabetic neuropathy which on investigations proved to be taboparesis. The case is described as a reminder that tabes dorsalis, although rare in the United Kingdom at present, must be included in the differential diagnosis of diabetic neuropathy. In addition, the tabo paresis developed over a 5-year period, in contrast to the slow development classically described in this condition.
\end{abstract}

\section{Introduction}

A general physician in the United Kingdom rarely has the opportunity to establish a new diagnosis of neurosyphilis. In the case described here, there was evidence of unusually rapid progression of the infection to late neurosyphilis. This patient was diabetic, and the tabetic pains which developed were at first put down to diabetic neuropathy.

\section{Case report}

An unmarried professional man with a university degree first presented in 1973 aged 45 years, when he was admitted for stabilization of his insulindependent diabetes which had been diagnosed 8 years previously. He volunteered that he had been treated for an anal wart at the age of 16 years, that he had been homosexual since the age of 12 years, and that he had received psychiatric treatment for a 'nervous breakdown' in 1967. In 1968, when he had been treated elsewhere for gonorrhoea, the cardiolipin Wasserman reaction (WR) and Reiter protein complement fixation test (RPCFT) had been negative. When examined in 1973 the only clinical neurological abnormality was absence of both ankle reflexes, and the WR and RPCFT were again negative.
Subsequently, control of his diabetes became progressively worse. An increasing tendency to make absurd mistakes in the management of his insulin regimen was associated with frequent episodes of hypo- and hyperglycaemia, and he became much more forgetful than usual. In March 1978 he began to complain of severe transient pains around the right side of the trunk, progressing over a few weeks to an unremitting, tight, pressure sensation with sharp stabbing exacerbations radiating to the right leg, and weakness of the lower limbs. It was felt that poor metabolic control had contributed to the development of a diabetic polyneuropathy, and it was suspected that recurrent hypoglycaemia had led to impairment of memory and intellect. He was therefore readmitted in June 1978 for assessment and stabilization.

On examination he was anxious, unkempt, looked inappropriately old, and had a poor memory for recent events. There were extensive, self-inflicted scratch marks, and he had obviously lost weight. Proximal weakness and wasting were noted in all limbs; ankle and abdominal reflexes were absent, and the plantar responses were extensor. The pupils were small, equal, regular and reacted normally to light and accommodation.

Abnormal results of investigations included evidence of mild normocytic normochromic anaemia $(\mathrm{Hb}, 11.2 \mathrm{~g} / \mathrm{dl})$, a raised ESR of $67 \mathrm{~mm} / \mathrm{hr}$, and inverse albumin/globulin ratio $(32: 34 \mathrm{~g} / \mathrm{dl})$. The following antibody tests for syphilis were now repeatedly positive: Venereal Disease Research Laboratory test (VDRL) $1: 128$; RPCFT; Treponema pallidum haemagglutination test (TPHA); and absorbed fluorescent treponemal antibody test (FTA-ABS) IgG and IgM. Examination of the CSF revealed increase in leucocytes $\left(29 \times 10^{6} / 1-\right.$ all mononuclear cells) and protein $(0.5 \mathrm{~g} / 1 ; \mathrm{IgG}, 0.27 \mathrm{~g} / \mathrm{l})$. The CSF, VDRL, RPCF, TPHA, and FTA-ABS 
IgG and IgM tests were all positive. The chest radiograph was normal.

Treatment with procaine penicillin 600000 units daily was given for 21 days with prednisone cover over the first 6 days. There was no Jarisch Herxheimer reaction. His weakness gradually lessened and during the next few weeks there was marked improvement in clarity of thought, together with progressive recovery of self-dependence and improvement in diabetic control. Psychological testing after one year, however, still showed evidence of mild residual brain damage, with no further change 6 months later.

\section{Discussion}

In 1978 it seemed likely that this patient's new symptoms were due to diabetic neuropathy and anxiety, and it was suspected that recurrent severe hypoglycaemic episodes underlay his intellectual impairment and forgetfulness. However, when the history of homosexuality came to light, further assessment and serological tests confirmed the diagnosis of taboparesis.

The importance of this case is twofold. First, it serves as a reminder that tabes dorsalis appears in the list of differential diagnoses of diabetic neuropathy. Second, there had been no definite clinical features, and the WR and RPCFT had been normal, only 5 years before the symptomatic onset of taboparesis. This contrasts with classical descriptions of neurosyphilis in which, although there are frequently CSF abnormalities during the early years, the underlying CNS involvement either remains asymptomatic or results in meningitis, perhaps with associated cranial nerve lesions (Parker, 1972). Tabes dorsalis and general paresis, however, typically develop many years later. The reason for the rapid progression to late neurosyphilis in the present patient is not clear, but the authors speculate that the impairment of immunity known to occur in. poorly controlled diabetes may have been a factors (Bagdade, 1976; Ludwig et al., 1976; Schernthaneg et al., 1977).

Even in non-diabetic patients, the diagnosis of neurosyphilis is more likely to be delayed nowadays than in the past. This is partly a result of its ine creasing rarity, but another reason is that the clinical picture may be atypical, perhaps because ant? microbials given for non-treponemal infection $\vec{\xi}$ modify the disease process (Willcox, 1964; Luxon Lees and Greenwood, 1976; Editorial, 1978). The case reported here raises the possibility that poorl| controlled diabetes might accelerate the progressiog of neurosyphilis. If so, then it is particularly imb portant to exclude syphilis at an early stage when 8 diabetic develops neurological symptoms.

\section{References}

Bagdade, J.D. (1976) Phagocytic and microbicidal functiog in diabetes mellitus. Acta endocrinologica. Copenhagen 83 (Suppl. 205), 27.

EDITORIAL (1978) Modified neurosyphilis. British Medicalt Journal, 2, 647.

Ludwig, H., Eibl, M., Schernthaner, G., Erd, Wo MAYR, W.R. (1976) Humoral immunodeficiency to bacterial antigens in patients with juvenile onset diabefe mellitus. Diabetologia, 12, 259.

Luxon, L., LeEs, A.J. \& Greenwood, R.J. (1979) Neuro syphilis today. Lancet, i, 90.

PARKER, J.D.J. (1972) Uncommon complications of earl⿱ syphilis. British Journal of Venereal Diseases, 48, 32.

Schernthaner, G., Ludwig, H., Zielinski, C.H. \& ENDler A.T. (1977) Cell mediated immunity to bacterial antigen in patients with insulin-dependent diabetes mellitus? Diabetes, 26 (Suppl. 1), 415.

Willcox, R.R. (1964) Textbook of Venereal Diseases and Treponematoses (2nd Edn), p. 212. Heinemann, London, 